\title{
Analisis Tingkat Kepuasan Pengguna Sistem Informasi Kerja Praktek dan Skripsi (SKKP) Menggunakan Metode End User Computing Satisfaction (EUCS)
}

\author{
Nanny Raras Setyoningrum \\ Sistem Informasi, STTI Tanjungpinang \\ nannysetyoningrum141@gmail.com
}

\begin{tabular}{l} 
Article Info \\
\hline Article history: \\
Received 2019-10-11 \\
Revised 2020-02-04 \\
Accepted 2020-02-13 \\
\hline
\end{tabular}

Keyword:

user satisfaction,

SKKP,

EUCS.

\begin{abstract}
The advantages of information technology in the education has developed a lot, especially in universities. An example of the application of tertiary level information technology is the delivery of information presented through the university's official website. One of the web-based systems owned by the STTI Tanjungpinang is the Sistem Informasi Kerja Praktek dan Skripsi (SKKP). With this technology, the process of submitting titles to the registration of practical work trials and student theses has been switched online. Analysis of the level of satisfaction is important to know the extent of expectations and perceptions of system users in an effort to achieve the perfection of an information system and can meet user expectations. One method in analyzing user satisfaction levels is end user computing satisfaction (EUCS). Dimensions in EUCS consist of content, accuracy, format, ease of use and timeliness. This type of research is descriptive research that is intended to describe the phenomena that exist, which took place at this time or in the past. Data collection methods included observation, interviews and distribution of questionnaires with a sample of 35 respondents who were active SKKP users. The results of the analysis of user satisfaction level SKKP STTI Tanjungpinang using the EUCS method of $78.69 \%$ with a gap of $21.31 \%$ means users are in the range of satisfied categories. From the five dimensions, the variable content has the smallest gap of $8.69 \%$ while the largest gap is in the accuracy variable, which is $32.02 \%$.
\end{abstract}

This is an open access article under the CC-BY-SA license.

\section{Pendahuluan}

Pemanfaatan teknologi informasi saat ini telah berkembang sangat pesat. Tidak dapat dipungkiri bahwa dengan beralih menggunakan sistem informasi akan memudahkan pekerjaan dan mengefisienkan waktu. Perusahaan berlomba-lomba meningkatkan pelayanan dengan memanfaatkan teknologi informasi. Pemanfaatan teknologi informasi cenderung diidentikkan kepada perumusan pekerjaan yang lebih cepat, akurat, efektif dan efisien baik dari segi waktu maupun biaya. Pemanfaatan teknologi informasi dalam dunia pendidikan telah banyak berkembang khususnya pada perguruan tinggi. Sebagai contoh penerapan teknologi informasi tingkat perguruan tinggi adalah penyampaian informasi disajikan melalui website resmi Perguruan Tinggi tersebut [1].
Sekolah Tinggi Teknologi Indonesia Tanjungpinang merupakan salah satu Perguruan Tinggi yang menggunakan sistem terintegrasi dengan teknologi informasi. Salah satu sistem berbasis web yang dimiliki oleh Sekolah Tinggi Teknologi Indonesia Tanjungpinang adalah sistem informasi kerja praktek dan skripsi. Dengan teknologi ini, proses pengajuan judul hingga pendaftaran sidang kerja praktek maupun skripsi mahasiswa dilakukan dengan daring.

Secara konteks kalimat sistem informasi terdiri dari dua kata, yaitu sistem dan informasi. Sistem adalah kumpulan elemen-elemen atau sumber daya yang saling berkaitan secata terpadu, terintegrasi dalam suatu hubungan tertentu untuk mencapai sebuah tujuan sedangkan informasi adalah data yang telah diproses atau data yang memiliki arti [2]. 
Dalam konsep SKKP, adanya integrasi dengan sistem informasi akademik maka memudahkan panitia dalam verifikasi peserta sidang kerja praktek dan skripsi. Selain itu juga memberikan kemudahan bagi pembimbing dan penguji untuk mengetahui mahasiswa yang mengambil mata kuliah kerja praktek dan skripsi dan juga mengetahui jadwal mahasiswa yang akan melaksanakan sidang kerja praktek dan skripsi. Mahasiswa juga lebih mudah dalam melakukan proses pengajuan judul serta pendaftaran sidang karena bisa dilakukan dimana saja selama dapat akses jaringan internet.

Analisis tingkat kepuasan ini penting untuk mengetahui sejauh mana harapan dan persepsi dari pengguna sistem dalam upaya mencapai kesempurnaan sebuah sistem informasi. Analisis tingkat kepuasan pengguna terhadap perangkat lunak sangat diperlukan agar dapat memenuhi harapan pengguna. Kebutuhan akan kualitas perangkat lunak yang baik sangat diinginkan baik oleh manajemen, pengelola perangkat lunak hingga pengguna akhir. Hal ini disebabkan karena kualitas perangkat lunak yang baik dapat berdampak pada peningkatan kepuasan pengguna akhir [3].

Kualitas suatu informasi tergantung ditentukan oleh tiga hal yaitu akurat, tepat waktu, dan relevan [4]. Berikut merupakan penjelasan mengenai tiga hal yang berpengaruh terhadap kualitas informasi :

1. Akurat (Accurate), informasi harus bebas dari kesalahan-kesalahan dan tidak menyesatkan serta jelas maksudnya. Informasi harus berasal dari sumber informasi sebab dapat saja ketika informasi tersebut belum sampai kepada penerima terjadi modifikasi informasi tanpa diketahui penerima informasi.

2. Tepat Waktu (Timelines), informasi yang datang pada si penerima tidak boleh terlambat. Informasi yang sudah usung tidak akan mempunyai nilai guna lagi karena informasi merupakan suatu landasan dalam pengambilan keputusan. Bila pengambilan keputusan terlambat maka dapat berakibat fatal bagi organisasi.

3. Relevan (Relevance), informasi harus relevan bermakna bahwa suatu informasi harus memiliki manfaat bagi pemakainya. Relevansi informasi untuk tiap-tiap individu berbeda tergantung pada yang menerima dan yang membutuhkan. Nilai informasi ditentukan oleh dua hal yaitu manfaat dan biaya. Suatu informasi dikatakan bernilai apabila manfaatnya lebih efektif dibandingkan dengan biaya mendapatkannya.

Terdapat beberapa cara untuk menganalisis tingkat kepuasan pengguna terhadap sistem informasi, salah satunya dengan menggunakan metode End User Computing Satisfaction (EUCS). Kepuasan pengguna merupakan salah satu indikator dari keberhasilan pengembangan sistem informasi. Sistem informasi dapat diandalkan apabila memiliki kualitas yang baik dan mampu memberikan kepuasan pada pemakainya [5].

Pengukuran terhadap kepuasan telah mempunyai sejarah yang panjang dalam disiplin ilmu sistem informasi. Sejumlah studi telah dilakukan untuk meng-capture keseluruhan evaluasi dimana pengguna akhir telah menganggap pengguna dari suatu sistem informasi (misalnya kepuasan) dan juga faktor-faktor yang membentuk kepuasan ini.

Definisi EUCS dari sebuah sistem informasi adalah evaluasi secara keseluruhan dari para pengguna sistem informasi yang berdasarkan pengalaman mereka dalam menggunakan sistem tersebut [6]. Metode EUCS menekankan evaluasi dari pengguna akhir terhadap aspek teknologi. Dimensi yang ada dalam EUCS terdiri dari isi (content), keakuratan (accuracy), format (format), kemudahan dalam menggunakan (ease of use) dan ketepatan waktu (timeliness), seperti pada gambar 1 .

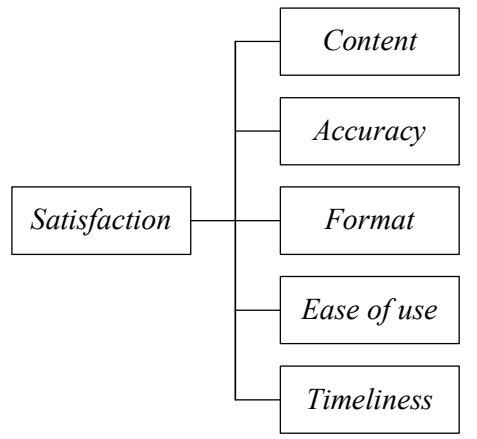

Gambar 1. Model Evaluasi EUCS

Penjelasan tiap dimensi yang diukur dengan metode EUCS menurut Doll dan Torkzadeh sebagai berikut.

1) Content (Isi)

Dimensi ini menjelaskan ukuran kepuasan pengguna akhir dengan melihat isi dari suatu sistem informasi Isi dalam sebuah sistem informasi haruslah sesuai dengan kebutuhan pengguna serta memiliki informasi terbaru. Semakin lengkap sebuah informasi maka dapat meningkatkan kepuasan pengguna.

2) Accuracy (Keakuratan)

Keakuratan yang dimaksud di sini adalah ketepatan sistem dalam mengolah input serta menghasilkan sebuah informasi. Sebuah sistem memiliki tingkat keakurasian yang baik, dapat dilihat dari jumlah error yang dihasilkan ketika mengolah data.

\section{3) Format (Format)}

Dimensi ini mengukur kepuasan pengguna akhir dalam menilai tampilan dan estetika dari antarmuka sistem. Tampilan yang menarik serta kemudahan dalam memahami dan menggunakan antar muka dapat meningkatkan kepuasan pengguna akhir dan dapat berpengaruh terhadap tingkat efektifitas pengguna.

4) Ease of Use (kemudahan dalam menggunakan sistem).

Kemudahan dalam menggunakan sistem merupakan hal yang penting karena kemudahan dalam menggunakan sistem meliputi keseluruhan proses dari awal sampai akhir yang terdiri dari proses memasukkan data, mengolah dan mencari informasi serta menampilkan data akhir yang akan digunakan oleh pengguna akhir. 


\section{5) Timeliness (waktu)}

Timeliness atau ketepatan waktu dalam menyajikan atau menyediakan informasi menjadi salah satu indikator kepuasan pengguna. Semakin cepat sebuah sistem mengolah input dan menghasilkan output dapat dijadikan tolak ukur penilaian apakah sistem tersebut tepat waktu atau real time [7].

Penelitian terkait metode End User Computing Satisfaction (EUCS) terkait analisis tingkat kepuasan pengguna Online Public Access Catalog (OPAC) pada Perpustakaan UIN SUSKA Riau. Hasil penelitian menunjukkan bahwa tingkat kepuasan pemustaka terhadap OPAC secara keseluruhan termasuk ke dalam kategori setuju. Pemustaka merasa puas menggunakan OPAC dengan nilai persentase sebesar $74,1 \%$ [8].

Penelitian yang pernah dilakukan pada Universitas Bandar Lampung untuk mengetahui sejauh mana tingkat kepuasan mahasiswa S-1 pada penggunaan Sistem Informasi Akademik dan Administrasi Terpadu (SIATer). Hasil penelitian menunjukkan bahwa mahasiswa belum sepenuhnya puas terhadap SIATer. Berdasarkan metode End User Computing Satisfaction (EUCS), terdapat beberapa indikator yang harus ditingkatkan agar dapat meningkatkan kepuasan mahasiswa yaitu indikator format, kemudahan penggunaan, dan ketepatan waktu [9].

Untuk mengetahui sejauh mana persepsi dan harapan pengguna serta tingkat kepuasan pengguna terhadap Sistem Informasi Kerja Praktek dan Skripsi (SKKP) Sekolah Tinggi Teknologi Indonesia Tanjungpinang maka penelitian ini dilakukan menggunakan metode yang sama dengan penelitian sebelumnya tersebut yaitu End User Computing Satisfaction (EUCS).

\section{Metodologi Penelitian}

Metode penelitian ini seperti terlihat pada gambar 2 berikut.

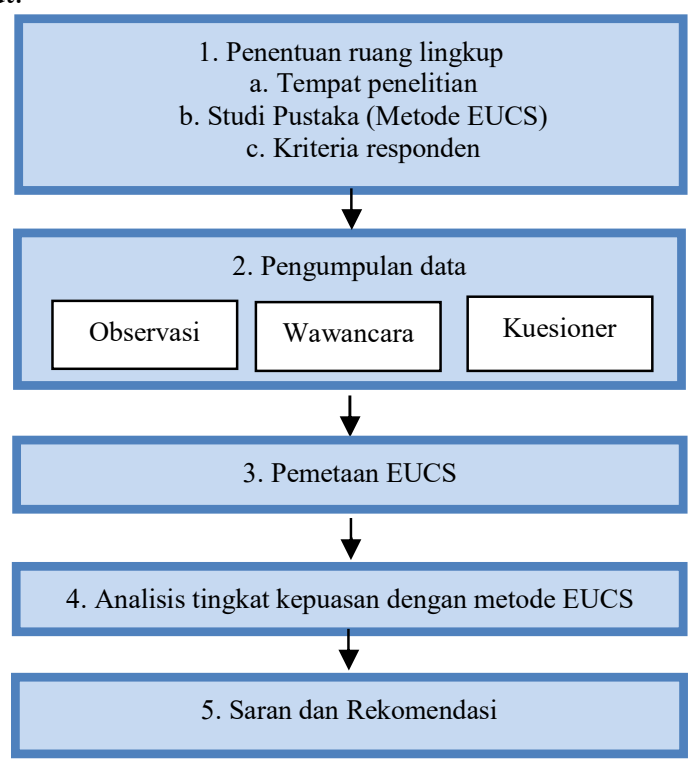

Gambar 2. Metode penelitian
Jenis penelitian ini ialah penelitian deskriptif. Penelitian deskriptif yaitu penelitian yang dimaksudkan untuk menggambarkan fenomena-fenomena yang ada, yang berlangsung pada saat ini atau saat yang lampau.

\section{A. Penentuan Ruang Lingkup}

Penentuan ruang lingkup dilakukan dengan melakukan kajian berdasarkan topik yang dipilih, tempat penelitian serta responden yang dipilih. Sampel penelitian ini yaitu para pengguna SKKP yang terdiri dari bagian akademik, program studi, selaku penyelenggara mata kuliah kerja praktek dan skripsi sekaligus panitia sidang kerja praktek dan skripsi. Selain itu juga staff Puskom sebagai admin, dosen dan mahasiswa dengan responden sebanyak 35 orang dengan teknik pengambilan sampel yang digunakan adalah purposive random sampling.

\section{B. Pengumpulan Data}

Pengumpulan data merupakan tahapan awal dalam melakukan analisis data dalam penelitian. Metode dalam pengumpulan data meliputi observasi, wawancara, kuesioner serta studi literatur. Wawancara adalah dengan menyediakan pedoman wawancara kepada responden mengenai tingkat kepuasan pengguna sistem informasi kerja praktek dan skripsi terkait persepsi dan harapan pengguna serta menyediakan kuesioner menggunakan metode end user computing satisfaction.

\section{Pemetaan metode End User Computing Satisfaction}

Sebelum kuesioner disebarkan terlebih dahulu akan dilakukan pemetaan terhadap metode End User Computing Satisfaction. Kuesioner yang disebarkan adalah kuesioner menggunakan dimensi EUCS. Selain itu juga menentukan kriteria penilaian sebagai dasar pengukuran kuesioner yaitu dengan skala Likert. Pembagian kriteria penilaian seperti terlihat pada table 1

TABEL I

KRITERIA PENILAIAN

\begin{tabular}{|c|c|l|c|}
\hline No & Simbol & \multicolumn{1}{|c|}{ Kriteria penilaian } & Skor \\
\hline 1 & SS & Sangat Setuju/Sangat Puas & 5 \\
\hline 2 & S & Setuju / Puas & 4 \\
\hline 3 & CS & Cukup Setuju/Cukup Puas & 3 \\
\hline 4 & TS & Tidak Setuju / Tidak Puas & 2 \\
\hline 5 & STS & $\begin{array}{l}\text { Sangat Tidak Setuju/ } \\
\text { Sangat Tidak Puas }\end{array}$ & 1 \\
\hline
\end{tabular}
Sumber: Riduwan (2009) [10]

\section{Analisis Tingkat Kepuasan}

Data kuesioner diolah untuk memperoleh hasil dari analisis tingkat kepuasan pengguna terhadap Sistem Informasi Kerja Praktek dan Skripsi menurut persepsi dan harapan pengguna. Sesuai penjelasan pada analisis tingkat kepuasan responden bahwa interval persentase tingkat kepuasan pengguna diinterpretasikan seperti pada tabel 2 . 
TABEL III

InTERPRETASi PERSENTASE TingKat KePUASAN PENGgunA

\begin{tabular}{|c|l|}
\hline Interval & \multicolumn{1}{c|}{ Kriteria } \\
\hline $81 \%-100 \%$ & Sangat Puas \\
\hline $61 \%-80 \%$ & Puas \\
\hline $41 \%-60 \%$ & Cukup Puas \\
\hline $21 \%-40 \%$ & Tidak Puas \\
\hline $0 \%-20 \%$ & Sangat Tidak Puas \\
\hline
\end{tabular}

\section{E. Saran dan Rekomendasi}

Setelah dilakukan pengolahan data selanjutnya peneliti menberikan saran dan rekomendasi kepada pihak Sekolah Tinggi Teknologi Indonesia Tanjungpinang sesuai hasil analisis tingkat kepuasan pengguna system informasi kerja praktek dan skripsi.

\section{Pembahasan}

Berdasarkan rekapitulasi kuesioner dengan pendekatan metode EUCS yang telah dilakukan sebelumnya, maka diperoleh skor criteria (skor ideal), total skor pengumpulan data variable dan besarnya persentase masing - masing variable penilaian kuesioner metode EUCS. Adapun langkah - langkah pada masing - masing dimensi sebagai berikut:

\section{A. Menentukan Skor Kriteria Masing-Masing Dimensi \\ 1) Content}

Pada dimensi content terdapat 6 item pertanyaan dimana masing - masing pertanyaan memiliki skor maksimal 5 dengan jumlah responden sebanyak 35 orang, sehingga diperolah skor criteria (skor ideal) sebagai berikut.

$$
\sum S K=5 \times 6 \times 35=1050
$$

\section{2) Accuracy}

Pada dimensi accuracy terdapat 3 item pertanyaan dimana masing - masing pertanyaan memiliki skor maksimal 5 dengan jumlah responden sebanyak 35 orang, sehingga diperolah skor criteria (skor ideal) sebagai berikut.

$$
\sum S K=5 \times 3 \times 35=525
$$

\section{3) Format}

Pada dimensi format terdapat 4 item pertanyaan dimana masing - masing pertanyaan memiliki skor maksimal 5 dengan jumlah responden sebanyak 35 orang, sehingga diperolah skor criteria (skor ideal) sebagai berikut.

\section{4) Easy of Use}

$$
\sum S K=5 \times 4 \times 35=700
$$

Pada dimensi easy of use terdapat 6 item pertanyaan dimana masing - masing pertanyaan memiliki skor maksimal 5 dengan jumlah responden sebanyak 35 orang, sehingga diperolah skor criteria (skor ideal) sebagai berikut.

$$
\sum S K=5 \times 6 \times 35=1050
$$

\section{5) Timeliness}

Pada dimensi timeliness terdapat 3 item pertanyaan dimana masing - masing pertanyaan memiliki skor maksimal 5 dengan jumlah responden sebanyak 35 orang, sehingga diperolah skor criteria (skor ideal) sebagai berikut.

$$
\sum S K=5 \times 3 \times 35=525
$$

\section{B. Menentukan Jumlah Total Skor Pengumpulan Data Variable.}

Berdasarkan rekapitulasi skor item pertanyaan sesuai pendekatan metode EUCS maka jumlah total skor pengumpulan data masing-masing dimensi disajikan dalam table 3 .

TABEL III

Jumlah Total Skor Pengumpulan Data Masing-Masing VARiabel

\begin{tabular}{|l|c|c|}
\hline \multirow{2}{*}{ Dimensi } & \multicolumn{2}{|c|}{ Skor Total } \\
\cline { 2 - 3 } & Persepsi Pengguna & Harapan Pengguna \\
\hline Content & 536 & 587 \\
\hline Accuracy & 172 & 253 \\
\hline Format & 238 & 326 \\
\hline Easy of Use & 331 & 431 \\
\hline Timeliness & 182 & 257 \\
\hline
\end{tabular}

C. Menentukan Besarnya Persentase Masing - Masing Dimensi

Berdasarkan jumlah total skor pengumpulan data variable selanjutnya menentukan besarnya persentase tingkat

\begin{tabular}{|c|c|c|c|}
\hline \multirow[b]{2}{*}{ Dimensi } & \multicolumn{2}{|c|}{ Skor Total } & \multirow{2}{*}{$\begin{array}{c}\text { Tingkat } \\
\text { Kepuasan } \\
(\%)\end{array}$} \\
\hline & $\begin{array}{c}\text { Persepsi } \\
\text { Pengguna }\end{array}$ & $\begin{array}{l}\text { Harapan } \\
\text { Pengguna } \\
\end{array}$ & \\
\hline Content & 536 & 587 & $91,31 \%$ \\
\hline Accuracy & 172 & 253 & $67,98 \%$ \\
\hline Format & 238 & 326 & $73,01 \%$ \\
\hline Easy of Use & 331 & 431 & $76,80 \%$ \\
\hline Timeliness & 182 & 257 & $70,82 \%$ \\
\hline
\end{tabular}
kepuasan pengguna dengan membandingkan antara persepsi dan harapan pengguna SKKP yang disajikan dalam tabel 4 .

TABEL IV

Persentase TingKat KePuasan Masing-Masing Variabel

Hasil analisis tingkat kepuasan responden terhadap kinerja dan harapan dari masing-masing variabel di atas dapat diolah lebih lanjut untuk mendapatkan nilai gap/selisih pada masing-masing dimensi. Hal ini dilakukan agar dapat

\begin{tabular}{|c|c|c|c|c|}
\hline \multirow[b]{2}{*}{ Dimensi } & \multicolumn{2}{|c|}{ Skor Total } & \multirow{2}{*}{$\begin{array}{c}\text { Tingkat } \\
\text { Kepuasan } \\
(\%)\end{array}$} & \multirow{2}{*}{$\begin{array}{c}\text { GAP/Selisish } \\
(\%)\end{array}$} \\
\hline & $\begin{array}{c}\text { Persepsi } \\
\text { Pengguna }\end{array}$ & $\begin{array}{l}\text { Harapan } \\
\text { Pengguna }\end{array}$ & & \\
\hline Content & 536 & 587 & $91,31 \%$ & $8,69 \%$ \\
\hline Accuracy & 172 & 253 & $67,98 \%$ & $32,02 \%$ \\
\hline Format & 238 & 326 & $73,01 \%$ & $26,99 \%$ \\
\hline Easy of Use & 331 & 431 & $76,80 \%$ & $23,20 \%$ \\
\hline Timeliness & 182 & 257 & $70,82 \%$ & $29,18 \%$ \\
\hline Total & 1459 & 1854 & $78,69 \%$ & $21,31 \%$ \\
\hline
\end{tabular}
dilakukan evaluasi terhadap SKKP. Nilai gap/selisih masingmasing dimensi disajikan dalam tabel 5.

TABEL V

NiLAi Gap/SElisih Masing-Masing Dimensi Metode Eucs 
Berdasarkan tabel 5, total tingkat kepuasan yang dirasakan pengguna SKKP menggunakan pendekatan metode EUCS sebesar 78,69\% dengan gap/selisish sebesar $21,31 \%$ artinya pengguna berada pada rentang kategori puas. Dari kelima dimensi tersebut variable content memiliki gap/selisih terkecil yaitu $8,69 \%$ sedangkan gap/selisih terbesar ada pada variable accuracy, yaitu sebesar 32,02\%.

\section{KESIMPULAN DAN SARAN}

\section{A. Kesimpulan}

Berdasarkan pembahasan dan hasil analisis data pada bab sebelumnya, maka diperoleh kesimpulan hasil analisis tingkat kepuasan pengguna Sistem Informasi Kerja Praktek dan Skripsi di Sekolah Tinggi Teknologi Indonesia Tanjungpinang menggunakan metode End User Computing Satisfaction menghasilkan tingkat kepuasan yang dirasakan pengguna sebesar $78,69 \%$ dengan gap/selisish sebesar $21,31 \%$ artinya pengguna berada pada rentang kategori puas, dimana dari kelima dimensi dalam metode End User Computing Satisfaction tersebut variable content memiliki gap/selisih terkecil yaitu $8,69 \%$ sedangkan gap/selisih terbesar ada pada variable accuracy, yaitu sebesar 32,02\%.

\section{B. Saran}

Berdasarkan hasil penelitian diatas, maka saran yang dapat peneliti berikan yaitu penelitian ini hanya menggunakan satu metode alangkah baiknya jika penelitianpenelitian selanjutnya dilakukan komparasi dari dua atau lebih metode. Penilaian perangkat lunak pada penelitian ini sebatas pada persepsi pengguna saja. Alangkah lebih baik apabila penilaian terhadap perangkat lunak bukan hanya menurut persepsi pengguna saja tetapi berdasarkan produk dari perangkat lunak itu sendiri.

\section{UCAPAN TERIMA KASIH}

Terima kasih kepada institusi Sekolah Tinggi Teknologi Indonesia Tanjungpinang yang telah mengijinkan kami melakukan penelitian terkait SKKP, Sistem Informasi Keja Praktek dan Skripsi.

\section{DAFTAR PUSTAKA}

[1] Hidayat, Rahmat, 2010, Cara praktis Membangun Website Gratis, PT. Elex Media Komputindo, Jakarta

[2] Gondodiyoto, Sanyoto, 2007, Audit Sistem Informasi + Pendekatan CobIT, Mitra Wacana Media,Jakarta

[3] Suyanto, M., 2005, Pengantar Teknologi Informasi Untuk Bisnis, Andi, Yogyakarta

[4] Sutarbi, T., 2012, Analisis Sistem Informasi, Andi, Yogyakarta

[5] Pressman, Roger, 2002, Rekayasa Perangkat Lunak Pendekatan Praktisi (Buku Satu), Andi, Yogyakarta

[6] Hutami, Rr. Rieka F., 2016, Analisis Kepuasan Pada Pengguna Sistem TCS Menggunakan Metode End User Computing Satisfaction (Studi Kasus: PT. TLK, Bandung),
Jurnal Manajemen Indonesia, ISSN: -, Vol. 16 - No.1 April, 2016

[7] Torkzadeh, Gholamreza dan Doll, William. 8 September 2017. Test-Retest Reliability of the End-User Computing Satisfaction Instrument. Decision Sciences. Vol. 22. Michigan State University, US. http://onlinelibrary.wiley.com/doi/10.1111/j.15405915.1991.tb01259.x/abstract

[8] Dalimunthe, Nurmaini dan Cici, Ismiati, 2016, Analisis Tingkat Kepuasan Pengguna Online Public Access Catalog $(O P A C)$ Dengan Metode EUCS (Studi Kasus : Perpustakaan UIN SUSKA Riau), Jurnal Rekayasa dan Manajemen Sistem Informasi, e-ISSN : 2502-8995, p-ISSN : 2460-8181, Vol.2, No.1, Februari 2016

[9] Putra, Jefri Krisna, 2014, Student Satisfaction Analysis of SIATer Using End User Computing Satisfaction (EUCS), $3^{\text {rd }}$ International Conference on Engineering \& Technology Development, ISSN : 2301-6590

[10] Riduwan, 2009, Skala Pengukuran Variabel-Variabel Penelitian, Alfabeta, Bandung 